\title{
Teachers' use of questioning and modelling comprehension skills in primary classrooms.
}

\author{
Mary Parker and Jane Hurry \\ Institute of Education, University of London
}

Corresponding author: Dr Mary Parker, School of Psychology and Human Development, Institute of Education, University of London, 25 Woburn square, London WC1H OAA

E-mailm.parker@ioe.ac.uk

\section{Introduction}

When Dolores Durkin (Durkin, 1979) undertook her classic observational study of reading instruction in American elementary schools in 1979, she noted that teachers spent almost all of the instructional time asking students questions, but little time teaching students the comprehension strategies that could be used to answer the questions. Since then there have been several major studies, for example (Palinscar and Brown, 1984; Scardmalia and Bereiter, 1985 this is where I wondered if we could have some more recent studies, Oakhill, J. (1994). Individual Differences in Children's Text Comprehension. In M.A Gernsbacher (Ed.), Handbook of Psycholinguistics (pp. 821-848). London: Academic Press.

Oakhill, J., \& Yuill, N. (1996). Higher order factors in comprehension disability: Processes and remediation. In C. Cornaldi \& J. Oakhill (Eds.), Reading comprehension difficulties: Processes and Intervention. Mahwah, NJ: Erlbaum. 
Perfetti, C., Marron, M., \& Foltz, P.W. (1996). Sources of Comprehension Failure: Theoretical Perspectives and Case Studies. In C. Cornoldi \& J. Oakhill (Eds.) Reading Comprehension Difficulties: Processes and interventions, 137-165.Hillsdale, NJ: Lawrence Erlbaum Assoc.

) also, it reads strangely at the moment as you have 'for example, and then references in brackets, rather than something like Palinscar and Brown (184), etc.which have focused specifically on the strategies which are involved in reading comprehension. To what extent are the findings from these studies reflected in teachers' practice? Would an observation study similar to Durkin's, but carried out twenty-five years later, show a change in the amount of instructional time spent by teachers asking questions and increased time spent teaching children explicit comprehension strategies such as generating questions or summarising?

This study looks at the ways in which teachers view the teaching of comprehension of text, within the National Literacy Strategy and their use of questioning in the classroom. We are particularly interested in establishing those strategies which are being used at Key Stage 2 to help children become skilled readers of narrative texts, the explicitness with which these are taught, and the types of interaction between teacher and children which occur during the shared reading of texts. Our focus is to observe the extent to which children are helped to interrogate the text and to become actively engaged in attempts to interpret what they read. Are teachers aware of strategies which encourage this interaction, and are they able to make these strategies explicit to the children in order to help them to gain mastery of the text?

\section{Questioning of text}

Most teachers are skilled and frequent readers of text who employ well rehearsed and effective comprehension strategies, without necessarily being aware that they are doing so. Pressley and Afflerbach ( 1995) emphasise that mature readers flexibly use a variety of 
processes as they read texts. Along with other researchers, for example same thing as I mention above, it doesn't seem right that the examples are in brackets (Rosenshine, 1980; Bereiter and Bird, 1985) Pressley and Afflerbach identify certain key strategies which distinguish skilled from less-skilled readers. In particular skilled readers use self-regulated strategies to generate their own questions about the text. Through this process, the reader gains a coherent understanding of the text, a hallmark of good comprehension (Oakhill, 1994). Bereiter and Bird (Bereiter and Bird, 1985)_describe this as 'demanding relationships' in response to unfamiliar material "the anticipatory questions expressed by skilled readers signals the setting up of watchers to ensure that the needed information will be recognized when it appears.” (p137)

There is evidence that explicit teaching of these reading strategies improves children's reading comprehension. Palinscar and Brown (Palinscar and Brown, 1984) identify four important self-regulating strategies for comprehension, which are: -generating questions about the text, predicting, clarifying, and summarising. In their 1984 study Palinscar and Brown provided specific instruction and practice in the use of these strategies to a group of seventh grade poor comprehenders (described as reciprocal teaching, to reflect the active role of the pupil in the teaching and learning process). This intervention led to significant gains on criterion tests of comprehension, reliable maintenance over time, generalisation to classroom comprehension tests, and improvement in standardized comprehension scores. Evaluations of other interventions which explicitly teach children how to generate questions and carry out higher level cognitive functions (Moore, 1988; Rosenshine, Meister and Chapman, 1996) support the Palinscar and Brown study and demonstrate that teaching children to question text is an effective tool for improving reading comprehension. 
To be effective these strategies need to be explicitly taught and practised by the children. Modelling the strategies by the teacher is not in itself sufficient to transfer skills. An intervention study (Bereiter and Bird, 1985) with children from Grades 7 and 8 found a significant advantage in reading comprehension for a treatment that combined teachers modelling thinking aloud strategies with direct instruction in identification and use of target strategies. However, neither strategy modelling alone, nor question-answer comprehension activities were found to be effective.

Since the pioneer work of Louise Rosenblatt ( 1938) there have been many studies ( for example Nystrand et al (1997), Butcher \& Kintsch (2003), Pardo (2004)) which emphasise that comprehension of text is a process which involves the reader in actively constructing meaning . For the individual this means interacting with the text through a combination of personal knowledge and experience, information in the text itself, and individual evaluative response

"The reader brings to the work personality traits, memories of past events, present needs and preoccupations, a particular mood of the moment, and a particular physical condition. These and many other elements in a never-to-be-duplicated combination determine his response to the peculiar contribution of the text." Rosenblatt: Literature as exploration (pp. 30-31)

The need for teachers to be aware of the importance of this transactional process is also emphasized by these writers. Laura Pardo (2004) in her article 'What every teacher needs to know about comprehension-'suggests that "Once teachers understand what is involved in comprehending and how the factors of reader, text, and context interact to create meaning, they can more easily teach their students to be effective comprehenders" p.272 
However this individualised approach to teaching comprehension may be difficult to promote within the wider context of the classroom.

UK national initiatives in education such as the National literacy strategy place considerable significance on whole class interactive teaching and the importance of classroom discourse. In the teaching and learning of comprehension skills this discourse would need to include a high level of reciprocity to enable pupils to engage in personal responses to text.

The benefits of dialogic classroom discourse to help pupils think and learn more effectively are recognised in the work of Alexander (2004) and research by Geekie (1999) in Australia indicates the value gain for pupils learning in literacy when teachers use talk explicitly to help children think independently.

However as Debra Myhill (2006) points out in her study of classroom discourse, teacher discourse will not support pupil learning if it is "concerned first and foremost with curriculum delivery and with leading pupils to a predetermined destination" (p 39). Her research which analyses classroom discourse in six middle/ primary schools in the UK found that "despite explicit educational initiatives which seek to improve the quality of teacher talk, the discourse patterns in whole class teaching remain very similar to previous studies" (p 36 ) She concludes that "whole class interactions appear to be characterised by teacher control and by curriculum content" and that "the potential of teacher talk for developing pupil understanding or for exploring pupils misconceptions has not yet been fully recognised." (p.39)

Within this context the current study explores a group of teachers' understanding of the comprehension process, and ways in which these are promoted in classroom discourse 


\section{Levels of comprehension}

In this study we identify comprehension of text at three levels; literal, inferential and evaluative, which correspond to the levels identified in the National Literacy Strategy (DfEE 1998)

We are interested in noting the emphasis which teachers place on each of the three levels of comprehension, and the strategies which are proposed for promoting these in classroom teaching.

The first level (literal) includes both 'surface' and 'propositional' understanding. At 'propositional' level understanding of the sentence follows a semantic analysis in which a propositional text base is formed. For some sentences this may be all that is necessary, but readers are often called to go beyond the specific words appearing in the sentence. To go from the propositional level of understanding to an interpretive level, inferences will be made. The second level can therefore be termed 'inferential'. The 'evaluative' level involves a personal response from the reader. At this third level the reader engages emotionally, sharing feelings with the author, and responding either positively or negatively to the text itself.

The importance of inference is well established in studies of children's comprehension. Writers such as Jane Oakhill (Oakhill and Garnham, 1988) suggest that the ability to use inference is a characteristic which distinguishes a skilled from a poor comprehender. She also suggests (Yuill and Oakhill, 1991) that younger children have the ability to make the same sorts of inferences as older ones, but that younger children may only exhibit their ability when prompted or questioned explicitly. 


\section{Methodology}

This study reports on one aspect of a larger research project which was funded by ESRC entitled 'The role of awareness in teaching and learning literacy and numeracy in Key Stage $2^{\prime}$

The aim of this project, which was undertaken between 2001 and 2004 in schools in London and Oxford, was to investigate the relationship between implicit and explicit knowledge in education. The researchers worked with pupils and teachers to investigate basic conceptual knowledge in aspects of literacy ( morphology and text comprehension) as well as in numeracy. A report of the full study can be found in.....

The data for the analysis of teaching of comprehension was taken from interviews and observations of fifty-one teachers of literacy at Key Stage 2 in 13 inner London primary schools. The data was collected in the Autumn term of 2001.

This data consists of:-

- Interviews with all fifty-one teachers who were asked to describe those strategies for teaching comprehension of text which they consider to be helpful and which they would use in their classroom.

- Video-taped observations of the same teachers in a class literacy session. Sessions of between forty-five minutes and one hour in length were observed and recorded for each teacher and a total of 86 separate literacy events were identified (Table I). From these videoed observations, those twelve literacy events which included shared reading and comprehension of fiction were selected for this study. The selected sessions represent the total amount of observed teaching of reading comprehension, apart from two sessions which concentrate on non-fiction, and two in which guided reading with small groups takes place. The literaey sessions were allobserved in the- 
Autmmn term of 2001 .

- A record was made of all the questions (from teachers and pupils) which occurred in these sessions, and of each teacher's responses to the children's answers. These were coded from the videoed observations of the 12 comprehension sessions.

\section{Table I around here}

\section{Data coding}

The classification and coding of the data from the interviews and observations is based on Content Analysis (Krippendorf 2004). This type of analysis is based on the assumption that words and phrases mentioned most often are those reflecting important concerns in communication. As the target of this study is to identify the levels of explicit awareness of teachers of those concepts affecting the teaching and learning of reading comprehension skills, the analysis takes as a premise that the number of references to a particular strategy is an indication of the level of awareness.

Both the interviews in which teachers were asked to describe strategies for teaching comprehension and the video-taped observations of classroom events were transcribed onto NVivo. NVivo is qualitative analysis software package which is devised to facilitate the exploration of qualitative data and is well suited to the coding of both interviews and the transcripts of interactive events. The use of video-taped material reduces the need for coders to make instant categorisation decisions about the interactions witnessed. (This was a criticism which was made of the design of the ORACLE studies (Galton et al 1999)). The videos were watched by all three researchers (including the authors of this study) and crossvalidation where each researcher coded the same data independently to ascertain inter-coder 
reliability of both interviews and classroom observations took place on several occasions.

The levels of agreement were good (above $80 \%$ in all cases).

\section{Interviews}

Using NVivo nodes were established which identified the types of questions, comprehension strategies, or other teaching methods each time they were mentioned by the individual teachers.

Here the researchers were able to cluster the teacher's responses into three categories: -

- Direct questioning - Responses in which the teacher mentions the use of direct questioning,

- Specific teaching -Responses in which the teacher mentions specific teaching of comprehension strategies,

- Other teaching methods - Responses in which other teaching methods are mentioned.

\section{Classroom observations}

All videotaped classroom observations were transcribed and entered on NVivo and every spoken interaction between teacher and children was analysed

From these transcriptions, the researchers clustered the teacher/child interactions into four main categories for comprehension: -

- Teacher questioning - Interactions in which the teachers asks a direct question.

- Teacher modelling -Interactions in which the teacher models a comprehension strategy while reading the text.

- Teaching explicit strategies - Interactions in which the teacher gives the children explicit strategies for comprehension. 
- Pupil questioning - Interactions in which a child initiates his/her own question about the text.

Within these four categories, nodes were established which identify a particular type of question, teacher modelling, or taught strategy. The number of examples which were coded for each node during the session provides an indication of the relative frequency with which particular strategies for teaching comprehension are being used in the classroom.

\section{Findings}

Teacher questioning.

Interviews

The teaching strategies referred to by the teachers in the comprehension section of the interview, are in response to a question which asks them about those strategies for teaching comprehension, which they find useful in the classroom.

Interviewer: Are there any teaching strategies or ways in which you try and help children to improve their comprehension in reading.

Analysis of the interviews shows that direct teacher questioning is considered to be an important strategy for teaching comprehension (see Table II). It is in fact the most frequently mentioned strategy and makes up $45 \%$ of the total references to teaching strategies in the interviews. However, children's questioning of text does not have a comparable priority. In the 51 interviews there are only 3 passages which mention strategies to encourage the children to generate questions. 


\section{Table II around here}

In table III we have grouped the different categories of question into the three levels of comprehension which were defined in the introduction. An analysis of the types of questioning to which teachers explicitly refer shows that questioning is aimed at inferential as well as propositional thinking skills.

\section{Table III around here}

In total $48 \%$ of references teachers mention propositional questioning, asking for the literal meaning of the text, or recall of facts.

Teacher: You've got to try and assess how well they've understood it by asking them quite specific closed questions like who is the main character, where did they go.

Teachers also seem to be well aware of the importance of developing inferential skills in children's comprehension. In 50\% of the references teachers mention inferential questioning (deductive, prediction and empathy).

Teacher "You could have questions that ask them to make inferences about the text so they have to read between the lines."

Teacher: "We do a lot of prediction what's going to happen next? So, we do that, we read a paragraph or a chapter, and say "What do you think's going to happen?"

The third level of comprehension, which is described as 'evaluative' - that is asking for opinions from the children about what they felt about the story, whether they enjoyed it, or thought it was well written - is almost ignored in the teachers' comments. There are only two references to any form of evaluative questioning. 
From analysis of these interviews therefore we gained the impression that teachers consider that teacher initiation of both literal and inferential, but not evaluative, questions are important strategies for teaching comprehension, but that teachers do not expect the children to ask questions themselves. In the second part of our study we tested these impressions against observations of classroom practice in comprehension lessons. A close match was found between the amount, levels, and type of questioning which was described by the teachers in interview and that which was observed in practice.

\section{Teacher questioning: observed sessions}

We found that $70 \%$ of the teaching behaviour in the observed 12 comprehension sessions is in the form of direct questioning from the teacher to the children about the text. (see Table IV) This confirms the findings from the interviews that direct oral questioning is the preferred method of teaching. An analysis of the styles of questions which are asked shows a very similar pattern of questioning to that referred to in the interviews, with a similar distribution of questions at literal, inferential and evaluative levels. The number of questions initiated by children is very low indeed, and this reflects the lack of reference to children generating questions reported in the interviews. Encouraging children to ask questions does not appear to be a priority for these teachers either in theory or in practice

\section{Table IV around here}

As can be seen from the examples of teachers' questions in Table V, the teacher questioning covers quite a wide range of styles. Two thirds of the questions in the observed session are asked in closed form. These are concerned with recall of factual information, deductive 
inference, background information, bibliographic information explanation of a word or phrase, or questions about genre. A third of the questions are open questions including empathy, prediction, open-ended inference, or a reference to the child's own experience.

\section{Table V around here}

There is a high level of consistency between the type of questioning observed in the 12 comprehension lessons, and the type of questioning referred to in the 51 interviews. In the interviews $48 \%$ of the references to teacher questioning were at the literal/propositional level, $50 \%$ were at inferential level, and $2 \%$ at evaluative level. In the observed comprehension lesson, $50 \%$ of the teachers' questions were at literal/propositional level, $48 \%$ at inferential level, and again $2 \%$ at evaluative level.

The propositional and inferential questions which are initiated by the teacher represent the type of questions a skilled reader might ask him/herself. This style of questioning therefore models a type of reading behaviour which may at some later stage be adopted by the children as they become more skilled readers. However the opportunity to practise such higher level self-questioning is neither offered to the children in the sessions nor mentioned as a teaching objective in the teacher interviews. The small representation of evaluative questions either in the interviews or the observations is surprising, as this level is specifically recognised in the NLS and included in the criteria for reading comprehension of both fiction and non-fiction throughout Key Stage 2. This rather confirms the role of the pupil as a passive one; their reactions to texts are not elicited. 
Questions about text which are initiated by the children contribute to only $5 \%$ of the interactions. This is a total of 15 questions over all, of which 8 occur in a single teaching session, in which one teacher specifically encourages the children to think of questions to ask about the text which they are reading.

\section{Teacher feedback to children's answers}

Given the prevalence of teacher questioning which we observed in the classrooms, we wanted to make a more detailed analysis of the pattern of discourse which follows on from this initial question. Studies of classroom discourse such as that of Sinclair and Coulthard (Sinclair and Coulthard, 1992) describe a proto-typical three part exchange structure consisting of initiation, in the form of teacher question, response in which the student attempts to answer the question, and evaluation, in which the teacher provides some form of feedback. If the teacher questioning is to be successful in promoting interactive dialogue we would need to see a fourth part to the exchange in the form of children's own reflections or questions.

For this analysis a record was made of each teachers' responses to the children's' answers. These were coded from the videoed observations of the 12 comprehension sessions, and include all the questions, which occurred in those sessions.

The teachers' responses are categorised into three groups

a) Responses which consist of a simple 'yes' or 'no' from the teacher, or where the child's answer is ignored. In this category there is no further dialogue

b) Responses in which the teacher goes on to give further explanation or to develop the child's answer, or to explain why it is not correct. In this category the dialogue is continued by the teacher. 
c) Responses in which the teacher asks the child to develop his/her answer, or to reconsider it, or give further explanation. In this category the dialogue is handed back to the child to continue.

Table VI shows the average score for the group of 12 teachers observed teaching comprehension. The number of responses in each category is calculated as a percentage of the total number of teacher responses occurring in each session.

\section{Table VI around here}

This table shows that the three-part exchange structure, described by Sinclair and Coulthard as 'teacher-led recitation' is the most prevalent form, in which the teacher response is used to evaluate rather than extend pupil contributions. The evidence of teachers dominating the dialogue in these comprehension sessions is strong. Only $18 \%$ of teacher's responses ask children to elaborate or develop their ideas further. The most frequent response (40\%) is an unelaborated affirmative 'yes', which does not interrupt the flow of the story but provides little opportunity for the exchange of ideas and opinions.

It is also clear from the table that most of the teacher questions $(85 \%)$ receive a correct answer from the children, which suggests that the questions are designed to elicit mainly convergent factual answers, possibly already be known to the children. They do not constitute a cognitive challenge.

For incorrect answers the usual response from the teacher $(6 \%)$ is to give an explanation of why the answer is wrong. Only $2 \%$ of the responses actually ask the child to reconsider the question, or to work out for him/herself why the answer may not be appropriate. 
However, further elaboration by the teacher of children's correct answers occurs quite frequently $(29 \%)$. In these instances a two stage teaching style is often used in which the initial question is presented as an opening which allows the teacher to go on to provide more background information.

Teacher What have the children noticed? And I don't think the man in the silken scarf, the keeper, thought that the children would notice this, but they obviously have. What have the children noticed? Emily

Child: The bear's feet are cut.

Teacher: Right, the way his feet are slightly torn and cut because it's had to walk from village to village to village, it's had to do all this walking and it hasn't had it's paws protected, so its feet are torn. That must be quite painful.

It can be seen from this example that not only is the child is not given the opportunity to develop her own answer about the bear's feet, but the follow-up question, which she might have posed herself, about what had happened to the bear's feet, is both provided and answered for her by the teacher.

\section{Teacher modelling}

Although the nature of teacher questioning presents a very consistent picture across both interview and classroom practice, this is not the case for teacher modelling. The importance of modelling comprehension strategies is hardly mentioned in the interview. However as can be seen from Table IV, it represents a significant proportion $(22 \%)$ of the observed teaching behaviour. 


\section{Table VII around here}

Analysis of the observation data shows a rich and varied use of good comprehension strategies being modelled by the teachers (see Table VII), including use of inference, setting up watchers, clarifying and summarising.

Teacher: 'Ok, so we think the story's going to be about Katie, the girl in the middle, and her two grandmothers, yeah? Let's find out.

Teacher: 'She's got big sticking out teeth and a very strict looking face, so she's probably not very approachable.'

Teacher: 'Let's see if that's true. (looks back at text).... 'One grey Sunday morning, Mr and Mrs Pickles..... yep, and they asked Sam, who was 18, to baby-sit his two younger brothers'

In these examples teachers use the form of 'thinking aloud' which is identified by Bereiter and Bird (Bereiter and Bird, 1985) as that used by a skilled reader to question the text. The fact that, when interviewed, teachers do not refer to the comprehension skills that they model, suggests that this knowledge may be implicit for them. As skilled readers themselves they use the strategies and model them for the children, but without being explicitly aware of them. In some ways this modelling of strategies resembles the earlier stage of the reciprocal teaching programme, but it falls short of an apprenticeship model because there are almost no instances of attempts to hand these higher reading skills over to the children. Analysis of the classroom observations shows only 9 instances ( $3 \%$ of observed interactions) in which comprehension strategies are made explicit and children are given an opportunity to practice these skills for themselves. (Table VIII) 


\section{Table VIII around here}

The authors conclusions section is the greatest strength of the paper. More recent literature is cited and built upon; conclusions are valid and do not overstate the findings; and suggestions for practice are made, working from the findings.

The only thing missing here is a qualification of the findings due to the number of teachers 12. The authors might mitigate this by stressing in the conclusion that although there are only 12 teachers, they feel that the conclusions are warranted given the correspondence of the observations with the interviews. That would be sufficient.

I didn't see where the qualification recommended by the $2^{\text {nd }}$ reviewer was mentioned but perhaps I missed it.

\section{Conclusions}

In this sample of London schools, direct oral questioning is shown to be the dominant strategy for teaching reading comprehension. Evidence for this comes both from the teacher interviews and from the amount of teaching time devoted to teacher questioning in the classroom observations. The prevalent form of questioning in the classroom is shown to be a 'recitation script'. This type of directive questioning tends to produce predictable correct answers, and only occasionally are teachers' questions used to assist pupils to develop more elaborated ideas. The range of the teachers' questions is wide and appropriate but, importantly we think, this places the pupil in too passive a role.

It could be that the format of the literacy hour itself constrains the teachers. It is suggested by Moyles (Moyles et al., 2003) that teachers are acutely aware of time pressures to meet the objectives within the literacy hour and when under such pressure tend to use a more directive form of teaching with less emphasis on active learning. However, this explanation is not supported by evidence from our study. The teachers whom we interviewed did not refer to time constraints, and their proposed teaching strategies reflect a lack of awareness of any advantage in making the children more active participants in the comprehension process. 
References to children's curiosity, response, or evaluation of the texts are also noticeably missing from the teacher interviews, further evidence of their conception of the pupil's role as a passive one.

Our analysis of classroom dialogue is supported by evidence from a study by Linda Hargreaves (Hargreaves et al., 2003), which evaluates interactive teaching in the National Literacy Strategy in England. Interestingly, her evidence shows that primary school teachers in England have in fact made their teaching of literacy more interactive, in a basic sense. In literacy sessions in both Key stages 1 and 2, they recorded an increase in the ratio of questions to statements since the first ORACLE project in 1976 (Galton et al, 1999) thus giving children more opportunity to answer questions. However, they also found that these responses were rarely extended and children were not engaging in genuine dialogue. They describe this type of interaction as 'surface interaction' characterised by a rapid exchange of question and answers. The tendency for teachers to dominate teacher/child interactions both in the amount and direction of the questioning, which is shown in our study suggests little change from the classrooms observed by Durkin in 1979.

Nonetheless, there are important ways in which the picture differs. The teaching described by Durkin is the model which was institutionalised in many primary reading schemes, with traditional comprehension questions and worksheets. The comprehension skills in the 1979 model focussed almost entirely on literal understanding of text. Although such teachers spoke of 'teaching' comprehension skills, Durkin comments that what they referred to almost exclusively was 'exercising' them. In contrast, the observation of teaching in this study shows that the importance of going beyond a literal understanding of the text and developing inferential skills is recognised and valued by almost all the teachers, and demonstrated both 
in the frequent references to inference in the interview and in the use of inferential questioning in the classroom. This reflects the tradition of people like Don Holdaway (1979) and Marie Clay (1991) who have influenced British practice and professional development. The kind of modelling observed in the literacy sessions could be developed as the first stage of a potent teaching strategy but it is likely to be much more effective if the strategies modelled are made explicit to the children and the children are given the opportunity to practice them. The opportunity for children to take over executive control from the teacher in an apprenticeship or scaffolding model is not a feature which is observed in the literacy sessions.

Although teachers demonstrate all the strategies of highly skilled readers, they did not discuss these when interviewed nor reflect on the strategies they used themselves, suggesting that their knowledge remains implicit. If they have not made these strategies explicit to themselves, they cannot make them explicit to the children. Reciprocal teaching offers a tried and tested technique which both makes key comprehension strategies explicit and requires children to actively apply the strategies.

The question is, why are these techniques not being applied in London classrooms (and probably English classrooms more generally)? Mroz and colleagues (Mroz, F.Hardman and F.Smith, 2000) offer one potential explanation. They point out, in their article on The Discourse of the Literacy Hour, that much of the emphasis in the NLS materials has been on subject knowledge and content in the curriculum rather than on pedagogy, so that teaching styles have only been superficially addressed. The evidence from our study suggests that teachers are not aware of alternative pedagogy in the teaching of comprehension skills. The findings from research which focuses on interactive strategies for reading comprehension are 
not reflected either in the teachers' awareness of teaching strategies nor in their practice. However, teachers' lack of explicit knowledge of the key reading comprehension strategies is also a content knowledge issue. It is possible that the literacy agenda has been dominated by the important and plentiful evidence of the role of phonics. Other dimensions of literacy development, including comprehension, have received less attention both from researchers and from policy makers. There is less research evidence available for the later stages of literacy development.

It is sometimes the case that educational researchers identify issues and make recommendations that are difficult for teachers to implement. For example, teachers may feel that whilst it may be desirable to have lots of challenging interaction in the classroom, it is difficult to manage in practice. However, as suggested by Angela Hobsbaum (Hobsbaum, Gamble and Reedy, 2002), reciprocal teaching fits well into a guided reading session, with children taking over the role of questioner and assuming responsibility for leading the group through each paragraph of the text. These sessions are already timetabled in to the recommended format of the literacy hour. Introducing a version of reciprocal teaching in small group sessions would be a practical way of managing the change from children as passive listeners to children as questioners. 


\section{$\underline{\text { References }}$}

Alexander, R (2004) Towards dialogic teaching: rethinking classroom talk. Cambridge:

Dialogos

\section{Appendix: Tables I-VIII}

Table I - Observed classroom literacy events $(n=86)$

\begin{tabular}{|l|l|l|}
\hline $\begin{array}{l}\text { Description of literacy events } \\
\text { (includes teacher instruction, class } \\
\text { discussion, children's } \\
\text { reading/writing activity and } \\
\text { plenary) }\end{array}$ & $\begin{array}{l}\text { Total number } \\
\text { of examples } \\
\text { observed }\end{array}$ & $\begin{array}{l}\text { Total amount of } \\
\text { time spent (in } \\
\text { minutes) }\end{array}$ \\
\hline Shared reading of narrative texts & 12 & 390 \\
\hline Reading non-fiction texts & 2 & 60 \\
\hline Guided reading & 2 & 30 \\
\hline $\begin{array}{l}\text { How to use dictionaries, glossaries } \\
\text { and reference books - alphabetical } \\
\text { order }\end{array}$ & 12 & 360 \\
\hline Note-taking from texts & 2 & 80 \\
\hline Drama & 1 & 60 \\
\hline Vocabulary work & 4 & 140 \\
\hline Writing based on narrative & 5 & 100 \\
\hline Genre writing & 19 & 740 \\
\hline Writing book/film reviews & 2 & 100 \\
\hline Poetry writing & 4 & 120 \\
\hline Spelling & 9 & 200 \\
\hline Punctuation and syntax & 7 & 180 \\
\hline Handwriting & 5 & 100 \\
\hline Total time of observed lessons & & $44 \mathrm{hrs}$ \\
\hline & & \\
\hline
\end{tabular}


Table II -Percentage of individual strategies for teaching comprehension mentioned in teacher responses $(n=51)$

\begin{tabular}{|l|l|}
\hline $\begin{array}{l}\text { Teaching strategies mentioned by } \\
\text { teachers in interviews }\end{array}$ & $\begin{array}{l}\text { Percentage of } \\
\text { total number } \\
\text { of references }\end{array}$ \\
\hline Use of direct oral questioning & \multicolumn{1}{|c|}{$45 \%$} \\
\hline Written exercises & $12 \%$ \\
\hline Teaching word meaning & $10 \%$ \\
\hline SATs directed activities & $8 \%$ \\
\hline Using art or drama & $6 \%$ \\
\hline Guided reading & $6 \%$ \\
\hline $\begin{array}{l}\text { Careful matching of text to reading } \\
\text { level }\end{array}$ & $3 \%$ \\
\hline $\begin{array}{l}\text { Teacher modelling strategies for } \\
\text { comprehension }\end{array}$ & $2 \%$ \\
\hline $\begin{array}{l}\text { Increasing children's background } \\
\text { knowledge }\end{array}$ & $2 \%$ \\
\hline Cloze exercises & $2 \%$ \\
\hline Recognising punctuation & $2 \%$ \\
\hline $\begin{array}{l}\text { Encouraging children to question } \\
\text { text }\end{array}$ & $2 \%$ \\
\hline DARTs activities & $1 \%$ \\
\hline $\begin{array}{l}\text { Pairing child with a good } \\
\text { comprehender }\end{array}$ & $1 \%$ \\
\hline $\begin{array}{l}\text { Total number of references to } \\
\text { teaching strategies }\end{array}$ & 137 \\
\hline
\end{tabular}

Table III - Teacher questioning $(n=51)$

\begin{tabular}{|l|l|}
\hline $\begin{array}{l}\text { Category of questions } \\
\text { specifically referred to by teachers } \\
\text { in interview }\end{array}$ & $\begin{array}{l}\text { Percentage of total } \\
\text { questions referred to in } \\
\text { interviews }\end{array}$ \\
\hline $\begin{array}{c}\text { Questioning at } \\
\text { literal/propositional level }\end{array}$ & $3 \%$ \\
\hline $\begin{array}{c}\text { Bibliographic details ( e.g. author, } \\
\text { title) }\end{array}$ & $24 \%$ \\
\hline Narrative - what is the story about? & $21 \%$ \\
\hline Recall of facts - closed questions & $16 \%$ \\
\hline Questioning at inferential level & $15 \%$ \\
\hline Inference- deductive & $16 \%$ \\
\hline Prediction & $3 \%$ \\
\hline Empathy/characterisation & \\
\hline Open-ended questioning & $2 \%$ \\
\hline Questioning at evaluative level & \\
\hline Evaluation & \\
\hline
\end{tabular}


Table IV - Coding of teaching behaviour from observed comprehension sessions ( $n=12)$

\begin{tabular}{|l|l|}
\hline Coding category from classroom observations & $\begin{array}{l}\text { Percentage of total } \\
\text { number of observed } \\
\text { interactions between } \\
\text { teacher and children } \\
\text { which relate to the text }\end{array}$ \\
\hline Teacher asks direct question & $70 \%$ \\
\hline $\begin{array}{l}\text { Teacher models comprehension strategy ( other } \\
\text { than by asking question) }\end{array}$ & $22 \%$ \\
\hline $\begin{array}{l}\text { Teacher provides children with explicit strategies } \\
\text { for comprehension }\end{array}$ & $3 \%$ \\
\hline Child asks question & $5 \%$ \\
\hline $\begin{array}{l}\text { Total number of observed interactions between } \\
\text { teacher and child which relate to the text }\end{array}$ & 293 \\
\hline
\end{tabular}

Table V - Teachers' direct questioning in observed comprehension sessions - percentages of types of questions asked $(n=12)$

\begin{tabular}{|c|c|c|}
\hline $\begin{array}{l}\text { Coding category } \\
\text { Teacher asks direct } \\
\text { question } \\
\text { Observed on teaching } \\
\text { videos }\end{array}$ & Sub codes & $\begin{array}{l}\text { Percentage } \\
\text { of total } \\
\text { number of } \\
\text { questions }\end{array}$ \\
\hline \multicolumn{3}{|l|}{$\begin{array}{l}\text { Questioning at } \\
\text { literal/propositional } \\
\text { level }\end{array}$} \\
\hline & Asks for recall of factual information from text & $25 \%$ \\
\hline & Asks for word or phrase meaning & $9 \%$ \\
\hline & Asks for bibliographic information & $5 \%$ \\
\hline & Asks for background information & $6 \%$ \\
\hline & Asks for explanation of metaphor & $1 \%$ \\
\hline & Asks for answer from child's own experience & $4 \%$ \\
\hline \multicolumn{3}{|l|}{$\begin{array}{l}\text { Questioning at } \\
\text { inferential level }\end{array}$} \\
\hline & Asks for deductive inference (known answer) & $18 \%$ \\
\hline & Asks for inference (empathy) & $9 \%$ \\
\hline & Asks for inference ( unknown answer) & $7 \%$ \\
\hline & Asks for information from pictures & $5 \%$ \\
\hline & Asks for prediction & $5 \%$ \\
\hline & Asks for answer from child's own experience & $4 \%$ \\
\hline $\begin{array}{l}\text { Questioning at } \\
\text { evaluative level }\end{array}$ & & \\
\hline
\end{tabular}




\begin{tabular}{|l|l|c|}
\hline & Asks about genre & $1 \%$ \\
\hline & Asks for point of view of author & $1 \%$ \\
\hline & Total number of direct teacher questions & 205 \\
\hline
\end{tabular}

Table VI - Teacher responses to children's answers. $(n=12)$

\begin{tabular}{|l|l|}
\hline $\begin{array}{l}\text { Teacher's responses to children's } \\
\text { answers }\end{array}$ & $\begin{array}{l}\text { Percentage of total number of responses } \\
\text { from comprehension. sessions }\end{array}$ \\
\hline T. responses to correct answers & $40 \%$ \\
\hline $\begin{array}{l}\text { 1a) Positive response without } \\
\text { elaboration (e.g. 'yes') }\end{array}$ & $29 \%$ \\
\hline $\begin{array}{l}\text { 1b) Positive response with } \\
\text { elaboration ( teacher develops } \\
\text { child's response) }\end{array}$ & $16 \%$ \\
\hline $\begin{array}{l}\text { 1c) Positive response with } \\
\text { elaboration (child asked to explain } \\
\text { or develop his response ) }\end{array}$ & $7 \%$ \\
\hline T. responses to incorrect answers & $\begin{array}{l}\text { 2a) Negative response with no } \\
\text { elaboration ( e.g.' no'), or response } \\
\text { ignored }\end{array}$ \\
\hline $\begin{array}{l}\text { 2b) Negative response with } \\
\text { elaboration ( teacher explains why } \\
\text { response is wrong ) }\end{array}$ & $6 \%$ \\
\hline $\begin{array}{l}\text { 2c) Negative response with } \\
\text { elaboration ( child is asked to } \\
\text { explain his response or given } \\
\text { guidelines for rethinking) }\end{array}$ & $2 \%$ \\
\hline
\end{tabular}

Table VII - Teacher modelling of comprehension strategies $(n=12)$

\begin{tabular}{|l|l|}
\hline Types of teacher modelling observed & $\begin{array}{l}\text { Percentage } \\
\text { of } \\
\text { instances }\end{array}$ \\
\hline Uses inference & $22 \%$ \\
\hline Sets up watcher & $16 \%$ \\
\hline Clarifies & $13 \%$ \\
\hline Summarises & $9 \%$ \\
\hline Relates text to own experience & $8 \%$ \\
\hline Rephrases & $8 \%$ \\
\hline Uses picture for information & $6 \%$ \\
\hline Demonstrates empathy & $6 \%$ \\
\hline Back-tracks to earlier part of text & $6 \%$ \\
\hline Predicts & $4 \%$ \\
\hline Creates mental picture & $2 \%$ \\
\hline & \\
\hline Total number of instances of teacher modelling & 67 \\
\hline & \\
\hline
\end{tabular}

Table VIII - Explicit strategies for comprehension $n(n=12)$ ;

\begin{tabular}{|l|l|}
\hline Children given explicit strategies & $\begin{array}{l}\text { Number of } \\
\text { instances in } \\
\text { comprehension }\end{array}$ \\
\hline
\end{tabular}




\begin{tabular}{|l|l|}
\hline & sessions \\
\hline Children asked to summarise & 5 \\
\hline $\begin{array}{l}\text { Children asked to look for unfamiliar words and } \\
\text { phrases }\end{array}$ & 2 \\
\hline Children asked to create a mental image & 1 \\
\hline Children asked to use pictures of context cues & 1 \\
\hline
\end{tabular}

